\title{
Molecular and IHC analysis of head and neck carcinomas associated with HPV infection
}

\author{
Stanek $\mathrm{L}^{1,2,3,4^{*}}$, Glendova $\mathrm{K}^{4^{*}}$, Tesarova $\mathrm{P}^{1}$, Gurlich $\mathrm{R}^{2}$, Holeckova $\mathrm{P}^{5}$, Musil $\mathrm{Z}^{6}$, Hrudka $\mathrm{J}^{7}$, \\ Pala $\mathrm{M}^{5}$, Mateicka $\mathrm{F}^{3}$, Chovanec $\mathrm{M}^{8}$
}

Department of Oncology, First Faculty of Medicine, Charles University and General University Hospital, Prague, Czech Republic. stanek.libor@seznam.cz

\begin{abstract}
Head and neck squamous cell carcinomas (HNSCC) are a highly heterogenous disease which can be induced by two main carcinogens - tobacco and/or alcohol, or by HR HPV infection. This work examined 60 paraffin-embedded biopsies of head and neck carcinomas after histological verification. HPV infection, including its specific types in various HNSCC areas, was studied using multiplex qPCR. Expression levels of $\mathrm{p} 16^{\mathrm{INK} 4 \mathrm{~A}}$ and $\mathrm{p} 53$ were detected by subsequent IHC analysis as being potential diagnostic markers. Based on the assumption that patients with HNSCC could benefit from anti-EGFR therapy (cetuximab), but the predictors are not yet defined, analyses of point mutations of ras genes (Kras, Nras) were carried out using multiplex qPCR and sequence analysis of the Braf gene. All statistical data were processed by Chí- $x^{2}$ test. HPV infection was detected in $23.34 \%$ of cases with HNSCC, of which $100 \%$ were HPV 16, which is the most frequently infection found in the oropharyngeal region. Using IHC analysis, a positive expression of P16 INK4A was detected in $100 \%$ of HPV-positive HNSCC while this expression was discovered to be highly correlated with HPV infection. Furthermore, a correlation between p53 and HPV-negative HNSCC was proved. The mutation incidence was the highest in the Kras gene (codon 12 and codon 146), Nras (codon 12) and Braf. A correlation between tumor location in the oropharyngeal region and Kras mutations was proved. The HPV infection correlated with Kras mutations in case of codon 146 but on the grounds of low amount of output data, these figures could be irrelevant. In one case, c. $1808 \mathrm{G}>\mathrm{A}$, protein $603 \mathrm{Arg}>\mathrm{GIn}$ mutation was found in the Braf gene but its correlation with head and neck carcinomas has not been described yet (Tab. 2, Fig. 2, Ref. 24). Text in PDF www.elis.sk. KEY WORDS: head and neck carcinomas, biopsy, HPV types, PCR, p16 INk4A, p53, molecular predictors, Kras, Nras, Braf.
\end{abstract}

\section{Introduction}

Head and neck carcinomas are the fourth most frequent type of tumors in men in European countries. In 2015 in the Czech Republic, 1,619 new cases of malignant tumors of the head and neck

${ }^{1}$ Department of Oncology, First Faculty of Medicine, Charles University and General University Hospital Prague, Czech Republic, ${ }^{2}$ Department of General Surgery, Third Faculty of Medicine, Charles University and University Hospital Kralovske Vinohrady, Prague, Czech Republic, ${ }^{3} \mathrm{St}$. Elizabeth University of Health and Social Work, Bratislava, Slovakia, ${ }^{4}$ Synlab czech, s.r.o., Prague, Czech Republic, ${ }^{5}$ Institute of Radiation Oncology, Na Bulovce Hospital, Prague, Czech Republic, 'Institute of Biology and Medical Genetics, First Faculty of Medicine, Charles University, Prague, Czech Republic, ${ }^{7}$ Institute of Pathology, Third Faculty of Medicine, Charles University and University Hospital Královské Vinohrady, Prague, Czech Republic, and ${ }^{8}$ Department of Otorhinolaryngology, Third Faculty of Medicine, Charles University and University Hospital Kralovske Vinohrady, Prague, Czech Republic

*Both authors contributed equally to this work

Address for correspondence: L. Stanek, Dr, Department of General Surgery, Third Faculty of Medicine, Charles University, Srobarova 50, CZ-100 34 Prague, Czech Republic.

Acknowledgement: This work was supported by the research program of Charles University PROGRES Q28 (Oncology). were registered in the Czech National Cancer Registry (CNCR), namely in 1,161 males and 458 females. As many as 553 men and 190 women died. According to the software for oncologic data visualization and data from the Czech National Cancer Registry processed by the Institute of Health Information and Statistics of the Czech Republic, the HNSCC incidence in both sexes is on the rise. The growth in the incidence of HNSCC was also registered in European countries and the USA (1).

Head and neck carcinomas start in the oral cavity, nasopharynx, oropharynx, larynx and hypopharynx. The oral cavity is lined with a mucous membrane consisting of thick non-keratinized stratified squamous epithelium. The nasopharynx is lined with pseudostratified columnar ciliated epithelium changing into non-keratinized squamous stratified epithelium in the area of the oropharynx. The larynx is lined with columnar ciliated epithelium and the hypopharynx with non-keratinized squamous stratified epithelium.

Approximately $90 \%$ of malignant tumors of the head and neck arise from the squamous epithelium of the above-mentioned areas. Between $80 \%$ and $90 \%$ of squamous cell carcinomas of the head and neck are caused by the long-term use of tobacco or alcohol. Other risk factors include socioeconomic status, dietary patterns, external conditions, and viruses such as papillomavirus, Epstein-Barr virus (EBV), cytomegalovirus (CMV) and human 
herpesvirus (HSV). Co-infections with two viruses often appear, while the most frequent are those with HPV and EBV (2). EBV infection is associated mainly with nasopharyngeal cancer and less frequently with oral and oropharyngeal cancer (3).

Human papillomavirus (HPV) is a double-stranded DNA virus with tropism for skin epithelium and mucosa of the genital and upper respiratory tract. HPV is mainly transmitted during sexual intercourse by entering the body through microtraumas in the mucous membrane. HPV can be classified as being low-risk or high-risk type according to its ability to induce carcinogenesis. Low-risk HPV types are responsible for warts (verruca vulgaris), condylomas and papillomas. High-risk HPV types are associated with anogenital malignancies and cancers of the head and neck.

Changes in the profile in patients with HNSCC suggest that HPV increases the malignancy risk and is causally associated with HNSCC independently of two main carcinogens - tobacco and alcohol. HPV-positive patients with HNSCC have different molecular characteristics and are associated with a better prognosis, better treatment response and higher survival rate. Patients with HNSCC coud benefit from anti-EGFR therapy (cetuximab) but the predictors are not yet defined as for example in colorectal carcinomas (CRC).

The protein $\mathrm{p} 16^{\mathrm{INK} 4 \mathrm{~A}}$ is a tumor suppressor and a cyclin-dependent kinase inhibitor that plays an important role in cell cycle regulation, specifically in the cell's progression from G1 phase to S phase. The complex of cyclin-dependent kinases (CDK) 4/6 and cyclin $\mathrm{D}$, which phosphorylates and thus inactivates $\mathrm{pRb}$ protein and starts proliferation, is necessary for entering the G1 phase. Physiologically, $\mathrm{p} 16^{\mathrm{INK} 4 \mathrm{~A}}$, which is negatively regulated by $\mathrm{pRb}$, creates a negative feedback, binds cyclin-dependent kinases $4 / 6$ and prevents their interaction with cyclin D. In this way, it prevents excessive expression of its own and other genes that are activated by E2F. Due to the controlled expression of these genes, the levels of p14 ${ }^{\mathrm{ARF}}$ remain low, which enables MDM2 (mouse double minute 2 homolog) protein to perform its normal role which is the regulation of $\mathrm{p} 53$, hence, the cell proliferates naturally. Owing to the ability of viral E6 oncogene to inactivate $\mathrm{pRb}$, the excessive expression of $\mathrm{p} 16^{\mathrm{INK} 4 \mathrm{~A}}$ occurs and thus acts as a significant biomarker in cervical pre-cancers and HPV-induced cancers (4).

HR HPV E6 and E7 proteins immortalize the cells. Their ability to associate with tumor suppressors $\mathrm{p} 53$ and $\mathrm{pRb}$ was proposed to be the way how viral proteins induce tumors.

Oncoprotein E6 stimulates the degradation of tumor suppressor protein p53 (5). Tumor suppressor protein p53 located on the small arm of chromosome 17 (17p13) controls cell growth by regulating the cell cycle progression and stress response leading to apoptosis. P53 also plays a role in carcinogenesis. Rather than from mutation, its dysregulation results from HPV infection and relevant viral proteins that inactivate it (E6). The inability of the cell to inhibit its growth and induce apoptosis leads to its genetic instability.

The degradation is executed by the interaction of viral E6 protein with E6-associated cellular protein. This interaction increases the affinity of E6-AP for p53, and ubiquitinated peptides are transferred to $\mathrm{p} 53$ protein. The degradation in $26 \mathrm{~S}$ proteasome follows and the cell can proliferate. E6 protein also interferes with other pro-apoptotic proteins such as Bak, Fass-associated death domain (Fadd) and procaspase 8 (6).

Viral E7 oncoprotein binds to tumor suppressor gene product, protein $\mathrm{pRb}$, which binds in its hypophosphorylated state to E2F transcription factor and thus regulates cell cycle progression. The binding of E7 to $\mathrm{pRb}$ liberates the transcription factor E2F. Thus, proliferation is initiated as well as the excessive expression of $\mathrm{p} 16^{\mathrm{INK} 4 \mathrm{~A}}(7)$ which is negatively regulated by $\mathrm{pRb}$ protein.

The absence of effective cell cycle progression inhibition via p16 $6^{\mathrm{INK} 4 \mathrm{~A}}$ can lead to its accumulation in the cell and higher levels of genes that are activated by E2F. The subsequent increase in $\mathrm{p} 14^{\mathrm{ARF}}$ levels can endanger MDM2 function in the process of $\mathrm{p} 53$ degradation which can lead to $\mathrm{p} 16^{\mathrm{INK} 4 \mathrm{~A}}$ excess and interruption of the cell cycle. This process is suppressed by high-risk E6 protein that degrades $\mathrm{p} 53$.

It is important to point out the differences between HPVpositive and HPV-negative HNSCC from the molecular point of view. In HPV-negative HNSCC tumor, the suppressor gene p53 is frequently mutated (16) or the chromosomal area $17 \mathrm{p} 13$ where the TP53 gene is located is lost. The loss of p53 function, as a result of the relevant gene mutation, leads to cell survival, genetic instability and increased expression of survivin (8) which works as a marker of worsened prognosis of these cancer patients. Similarly, the chromosomal area 9p21 where the tumor suppressor gene $\mathrm{p} 16^{\mathrm{INK} 4 \mathrm{~A}}$ is located is lost at the very beginning of carcinogenesis, which leads to its loss.

In HPV-positive HNSCC, TP53 gene mutations are less probable than in HPV-negative HNSCC. HPV E6 protein causes inactivation of p53 protein, not its mutation (5). In HPV-positive tumors there is no $\mathrm{p} 16^{\mathrm{INK} 4 \mathrm{~A}}$ loss but as a result of $\mathrm{pRb}$ being degraded by $\mathrm{E} 7$ protein, there is $\mathrm{p} 16^{\mathrm{INK} 4 \mathrm{~A}}$ overproduction. The identification of various molecular genetic profiles that are caused by different environmental exposures supports the idea that HNSCC are a heterogeneous group of tumors which can be categorized by HPV status and according to WHO are considered to be different entities. The fact that HPV-positive tumors are associated with a better prognosis and have different molecular characteristics is an important clinical benefit. HPV-positive patients respond better to the treatment and have a higher survival rate than patients with HPV-negative tumors $(9,10)$.

The study of Danish scientists suggests that HPV status in tumors located out of the oropharynx does not have a prognostic impact on the result of primary radiotherapy. According to this study, it is possible to use less aggressive treatment in patients with HPV-positive tumors of the oropharynx and thus improve the quality of their lives (1).

\section{Materials and methods}

The aim of this work was to study HPV infection in various areas of head and neck carcinomas using retrospective analysis, compare the incidence and frequency of HPV types, determine the expression of $\mathrm{p} 16 \mathrm{INK} 4 \mathrm{~A}$ protein and $\mathrm{p} 53$ protein, and find their possible correlation with HPV infection, as well as on the 
basis of these data to suggest their possible use as potential diagnostic biomarkers. Mutations of the RAS gene family are tested, specifically those of Kras and Nras in exon 2, 3 and 4, and Braf gene, to study the correlation of these genes' mutations with risk factors and HPV infection and their possible role of potential predictors of cetuximab-targeted therapy.

The overall cohort consisted of $60 \mathrm{pa}-$ tients with histologically confirmed head and neck carcinomas. There were tumors of the oral cavity (oral-dental socket, hard palate, buccal area and tongue, tumors of the oropharynx (OP - oropharyngeal) and tumors of the larynx (non-OP - non-oropharyngeal). The group of patients aged between 29 and 96 consisted of 48 men (80\%) - median age 64.89 years and 12
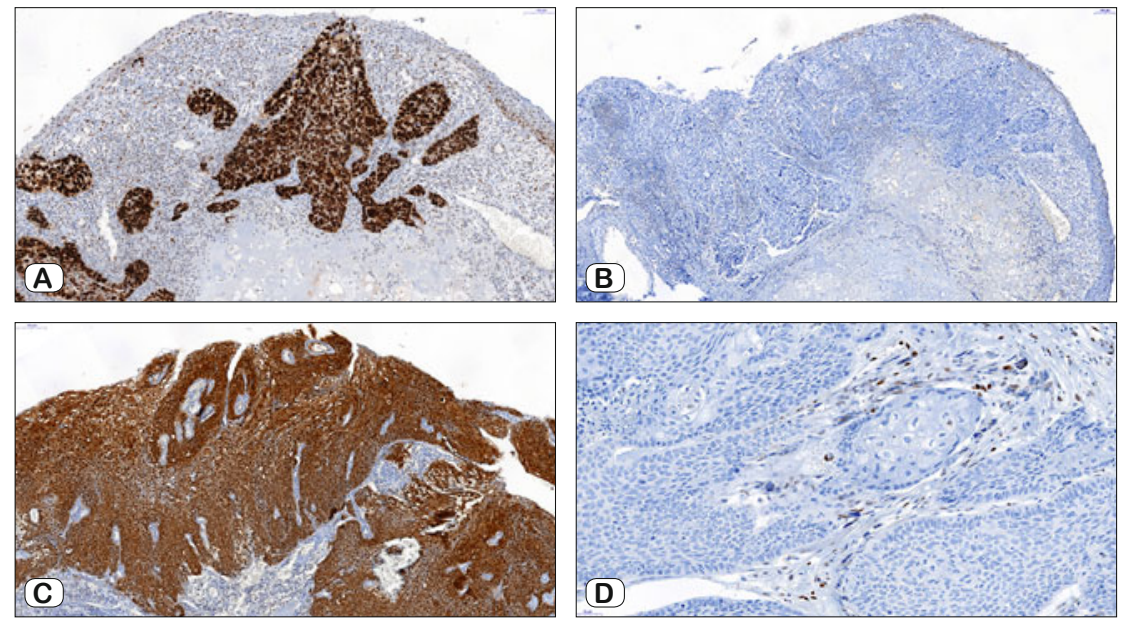

Fig. 1. A) HPV-positive p16INK4A-positive cell carcinoma squamous cell. B) HPV-negative squamous cell carcinoma with negative p16INK4A. C) HPV-negative p53 carcinoma-positive cell carcinoma. D) HPV-positive p53-negative carcinoma cell (yellow arrow). women $(20 \%)$ - median age 59.16 years.

Eight patients already died. Thirty-two patients (out of 60; 53.4\%) used tobacco in the past. The percentage of patients who consumed alcohol in the past could not be defined as this is a retrospective study and patients were not chosen on the basis of a questionnaire. Histologically, the tumors were squamous cell carcinomas. In all patients, the tissue was taken for analysis from the primary tumor site, including resection margins.

As many as 4-6 tissue sections were used for isolation after previous deparaffinization using QIAamp ${ }^{\circledR}$ DNA Mini Kit (250); Dynex.

HPV analysis was carried out using quantitative multiplex PCR in real time, Real-Time High-Risk HPV PCR (96); KitGen in RotorGene Q; Dynex. The reaction is based on the system of pathogen-specific primers and probes that recognize their specific target during quantitative Real-Time PCR (Tab. 1). The internal control (IC) detects authentic human genes. To maintain the maximal sensitivity of the diagnostic set, the internal control is amplified in a separate test tube.

IHC was carried out on paraffin tissue sections, 3-4 $\mu \mathrm{m}$ wide. P16 detection was performed using mouse monoclonal antibody supplied by GenomeME, clone IHC016. P53 detection was performed using the antibody supplied by Roche, clone DO-7. In both cases, the data were robotically analyzed on BenchMark ULTRA (Ventana Medical Systems; Roche).

For detecting the somatic point mutations of Kras and Nras gene codons 12/13 in exon 2, codon 61 in exon 3 and codon 146 in exon 4, the kit QClamp ${ }^{\mathrm{TM}}$ KRAS and NRAS Codon Specific Mutation Detection Kit; DiaCarta on LightCycler 480 II, Roche were used.

Tab. 1. The system of pathogen-specific primers and probes that recognize their specific target during quantitative Real-Time PCR.

\begin{tabular}{lc}
\hline Reverse primer & 5'CTGTTCAAACTGATGGGACCC 3' \\
\hline Forward primer & 5'TGCTTGCTCTGATAGGAAAATG 3' \\
\hline
\end{tabular}

Sanger sequencing was used for detecting mutations in exon 15 of the Braf gene. Primers were proposed on the basis of GenBan sequences using Primer 3 software, including intron-exon boundaries (Tab. 1). PCR products were purified and sequenced using BigDye Terminator v.3.1 Cycle Sequencing Kit (Applied Biosystems) on ABI Prism 3130 Avant Genetic Analyzer.

Chí- $\mathrm{x}^{2}$ test was used for statistical evaluation of HPV, p16, p53 and Kras, Nras and Braf mutations. Software Excel, Microsoft ${ }^{\circledR}$ was used for statistical analysis. Variables with $\mathrm{p}<0.05$ were considered statistically significant.

\section{Results and discussion}

HPV genome was detected in 14/60 (23.34 \%) patients and HPV type 16 was identified in 14/14 (100\%) cases. The detection of HPV positivity varied in particular locations of HNSCC. There was a difference in HPV prevalence between oral, OP and non-OP carcinomas. As many as 5/40 oral carcinomas were HPV-positive, 6/10 OP carcinomas were HPV-positive, and 3/10 non-OP carcinomas were HPV-positive The correlation between cancer location and HPV status was detected only in case of the oropharynx ( $\mathrm{p}=$ $0.006)$ and tongue $(p=0.052)$ while only marginal interactions were found in other HNSCC locations.

More HPV-positive HNSCC were found in males $(85.7 \%)$ than in females $(14.3 \%)$, thus the correlation with gender was shown to be strong $(p=0.003)$. In HPV-negative tumors, no correlation with gender was detected $(p=0.768)$. The age in male patients did not play any role in HPV-positive tumor location $(\mathrm{p}=0.720)$ (Figs 1 and 2).

The correlation between age and HPV-positive tumors was marginal in both genders $(p=0.065)$. The location of HPV-positive tumors did not correlate with age $(\mathrm{p}=0.405)$.

A positive p16 expression was detected in 17/60 (28.33\%) cases of HNSCC. Thep $16^{\mathrm{INK} 4 \mathrm{~A}}$ expression was not detected in $43 / 60(71.67 \%)$ cases, and in 2/43 (4.65\%) cases, it was not 

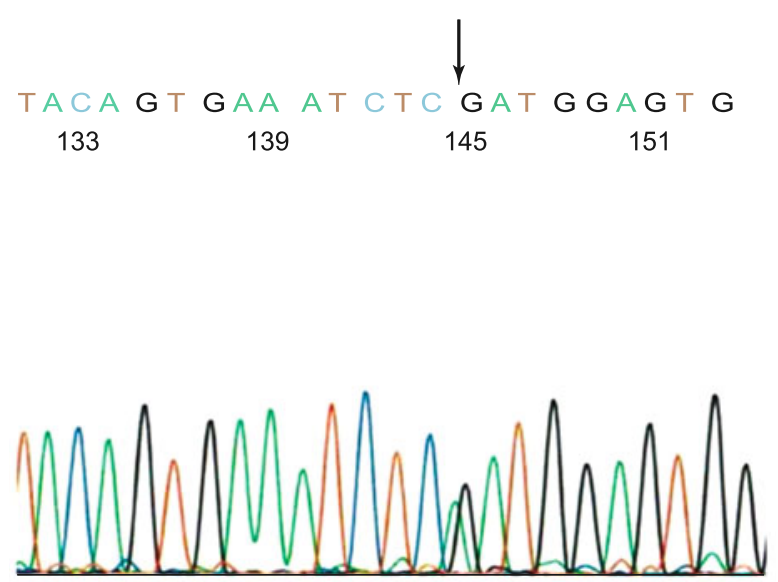

Fig. 2 Sequence from mutation analysis of c. $1808 \mathrm{G}>\mathrm{A}$, protein 603 Arg > GIn.

possible to specify $\mathrm{p} 16^{\mathrm{INK} 4 \mathrm{~A}}$ expression. The latter cases were thus regarded as negative. The $\mathrm{p} 16^{\mathrm{INK} 4 \mathrm{~A}}$ expression was detected in 14/14 HPV-positive samples (100 \%) and in 3/46 HPV-negative samples $(6.52 \%)$. The correlation between the positive expression of $16^{\text {INK4A }}$ and HPV status was found to be strong $(\mathrm{p} \leq 0.001)$. The correlation between $\mathrm{p} 16^{\mathrm{INK} 4 \mathrm{~A}}$ expression and gender / age imitates the HPV incidence.

The $\mathrm{p} 53$ expression was detected as positive in $25 / 60(41.7 \%)$ cases of HNSCC. The p53 expression was not detected in $35 / 60$ $(58.3 \%)$ cases, while in 5/35 (14.3\%) cases, it could not be identified. The latter cases were thus regarded as negative.

The $\mathrm{p} 53$ expression was detected in 2/14 HPV-positive samples (14.3\%) and in 23/46 HPV-negative samples (50 \%). A simultaneously positive expression of $\mathrm{p} 16$ protein and $\mathrm{p} 53$ protein was found in $2 \mathrm{HPV}$-positive tumors and in one HPV-negative tumor.

A marginal correlation between positive expression of $\mathrm{p} 53$ and HPV-negative tumors was found $(p=0.069)$. The interaction between location of HPV-negative tumors and positive $\mathrm{p} 53$ expression was found only in cases with affliction of hard palate $(p=0.042)$ and buccal area $(p=0.049)$. The correlation between age and positive $\mathrm{p} 53$ expression was not found $(\mathrm{p}=0.328)$ as well as the correlation between $\mathrm{p} 53$ expression and gender $(\mathrm{p}=0.317)$ and smoking $(\mathrm{p}=0.590)$ (Tab. 2).
The mutation analysis of the Kras gene - 5/60 cases is not included into the study results on the grounds of invalid results of real-time PCR. On that account, the overall cohort consists of 55 patients.

The Kras mutation was detected in $7 / 55$ tumors (12.72\%). As many as $48 / 55$ tumors ( $87.28 \%$ ) were detected as wild type. Mutations were found in two codons, namely in codon 12 exon 2 and codon 146 exon 4. Mutations in codon 12 were present in $5 / 7$ tumors $(71.42 \%)$ while those in codon 146 were in $2 / 7$ tumors $(28.58 \%)$.

Age and gender were not related to mutations in codon 12 $(\mathrm{p}=0.263 ; \mathrm{p}=0.525)$ and mutations in codon $146(\mathrm{p}=0.479 ; \mathrm{p}$ $=0.487$ ).

The correlation between tumor locations and codon 12 mutations was found only in case of oropharynx affliction $(p \leq 0.011)$. The correlation between mutations and oropharyngeal tumors was found also in codon $146(\mathrm{p} \leq 0.003)$.

Regarding HPV status, the codon 12 mutation was found only in one HPV-positive tumor $(\mathrm{p}=0.779)$. The codon 146 mutation was found in two HPV-positive tumors $(p=0.041)$, thus HPVpositive tumors and codon 146 mutations correlate.

Kras mutations (codon 12 and codon 146) strongly correlated with smoking ( $\mathrm{p} \leq 0.001)$.

The mutation analysis of the Nras gene (6/60 cases) is not included into the study results on the grounds of invalid results of real-time PCR. On that account, the overall cohort consists of 54 cases.

Nras mutations in exon 2 were detected in 2/54 tumors (3.7 \%). Nras was detected as a wild type (wt) in 52/54 tumors ( $96.3 \%$ ) Mutations were detected only in codon 12 .

No interactions between codon 12 mutation and gender $(\mathrm{p}=$ $0.298)$ and codon 12 mutation and age $(\mathrm{p}=0.476)$ were found.

The codon 12 mutation was detected only in one HPV-positive tumor $(\mathrm{p}=0.437)$. Smoking did not correlate with Nras mutations.

Statistically, no correlation between Nras and Kras mutations and HPV infection was found $(\mathrm{p}=0.190)$.

Mutation analysis of the Braf gene (6/60 cases) are not included into the study results on the grounds of invalid results of real-time PCR. On that account, the overall cohort consists of 54 patients. The Braf gene mutation (c.1808 G>A) was detected in one tumor $(1.85 \%)$.

Tab. 2. The correlation between age and positive p53 expression and the correlation between p53 expression and gender and smoking.

\begin{tabular}{|c|c|c|c|c|c|c|}
\hline & $\begin{array}{c}\mathrm{p} 16^{\mathrm{INK} 4 \mathrm{~A}}+ \\
\mathrm{n}=17(\%)\end{array}$ & $\begin{array}{c}\mathrm{p} 16^{\mathrm{INK} 4 \mathrm{~A}}- \\
\mathrm{n}=43(\%)\end{array}$ & $\begin{array}{c}\text { P53+ } \\
\mathrm{n}=25(\%)\end{array}$ & $\begin{array}{c}\text { P53- } \\
\mathrm{n}=35(\%)\end{array}$ & $\begin{array}{c}\text { HPV+ } \\
\mathrm{n}=14(\%)\end{array}$ & $\begin{array}{c}\text { HPV- } \\
\mathrm{n}=46(\%)\end{array}$ \\
\hline \multicolumn{7}{|l|}{ Status $\mathrm{p} 16^{\mathrm{INK} 4 \mathrm{~A}}$} \\
\hline Negative & - & - & $22(88)$ & $22(62.85)$ & $0(0)$ & $44(95.65)$ \\
\hline Positive & - & - & $3(12)$ & $13(37.15)$ & $14(100)$ & $2(4.35)$ \\
\hline \multicolumn{7}{|l|}{ Status p53 } \\
\hline Negative & $14(82.35)$ & $21(48.83)$ & - & - & $12(85.71)$ & $23(50)$ \\
\hline Positive & $3(17.65)$ & $22(51.17)$ & - & - & $2(14.29)$ & $23(50)$ \\
\hline \multicolumn{7}{|l|}{ Status HPV } \\
\hline Negative & $3(17.64)$ & $43(100)$ & $23(92)$ & $23(65.72)$ & - & - \\
\hline Positive & $14(82.36)$ & $0(0)$ & $2(8)$ & $12(34.28)$ & - & - \\
\hline
\end{tabular}


Gender and age did not correlate with Braf mutations ( $p=$ 0.613 and $p=0.082$, respectively). Regarding location, a marginal correlation was found only in case of larynx affliction ( $p$ $=0.054)$. The Braf mutation was detected in one HPV-positive tumor $(\mathrm{p} \leq 0.001)$. Smoking was not associated with Braf mutations $(\mathrm{p}=0.335)$.

The head and neck carcinomas are the fourth most frequent malignancies in men from European countries. Papillomaviruses increase the risk of HNSCC by changing the molecular profile of patients. HPV infection is causally associated with HNSCC independently of two major etiologic factors, tobacco and alcohol.

In this study we evaluated the prevalence of HPV infection as well as analyzed HPV types in 60 patients with HNSCC. HPV infection was detected in 14 patients and solely HPV type 16 infection was identified. This type is frequently detected in HNSCC and is also the most frequent type causing cervical cancer in women $(11,12)$.

Differences were found in HPV infection incidence according to the location. The most of HPV-positive tumors were found in the oropharyngeal area where HPV-positive tumors represented $42.8 \%$ of all cases. The incidence in other studied areas was lower (oral tumors $-35.7 \%$, non-oropharyngeal tumors $-21.5 \%$ ).

Our results parallel the observations of previous studies of Kreimer et al and Faust et al, the results of whom confirm that the most frequent location of HPV infection was in the oropharynx, followed by oral cavity and larynx $(13,14)$.

HPV infection, especially he high-risk types play an important role in the molecular mechanisms of carcinogenesis by means of viral oncoproteins E6 and E7. E6 binds to p53 and determines it to proteasome-dependent degradation whereas E7 binds and inactivates $\mathrm{pRb}$ tumor suppressor, which leads to excessive p16 expression via the loss of negative feedback. P16 and 553 are tumor suppressor genes and key targets in the loss of cell cycle control.

In this study, similarly to that conducted by Wittekindt et al, the p16 expression was observed in all HPV-positive HNSCC (15). Wittekindt studied the correlation between HPV-positive and p16-positive HNSCC and found p16 expression to be present in all HPV-positive neoplastic cells.

The p16 immunoreactivity probably starts from transcriptionally active HPV infection which is supported by the fact that HPV-positive HNSCC makes up a biologically different tumor entity. The p16 immunohistochemical staining of HNSCC can be used as a reliable diagnostic biomarker of HPV-positive HNSCC as well as in routine diagnostic histopathology.

In HPV-negative head and neck carcinomas, the tumor suppressor gene $\mathrm{p} 53$ is frequently mutated (16). In HPV-positive HNSCC, TP53 mutations are less probable because the protein p53 is inactivated rather than mutated, or overexpressed by means of HPV E6 protein (5).

In this study, a positive expression of p53 was detected in $38.4 \%$ of HPV-negative tumors and only in $3.3 \%$ of HPV-positive HNSCC. Risk factors such as age and gender did not play any role in positive expression of $\mathrm{p} 53$. Regarding the location, an association of non-HPV and positive expression of $\mathrm{p} 53$ was found in the hard palate and buccal areas. Nevertheless, no bibliography is available to compare these data.

In the older study of Nadal et al, the HPV status in HNSCC was not taken into consideration. The study only demonstrated that the p53 expression can be the initial genetic change in the development of squamous cell carcinomas (17) and gave information about the progression of the disease. On the basis of this information, our study was aimed at finding out if p53 expression in squamous cell carcinomas correlated with the HPV status. The results show a certain correlation between the $\mathrm{p} 53$-positive expression and HPV-negative status of tumors. It can be caused by smoking. More than a half of HPV-negative / p53-positive patients smoked in the past and smoking of tobacco increases the frequency of p53 mutations (18). The p53 mutant is usually more stable but can be more expressed in neoplastic tissue than in normal tissue.

The RAS family oncogenes (Hras, Kras a Nras) are strongly involved in cancer pathogenesis and thus highly relevant. In case of colorectal cancer, it was proved that patients with these genes' mutations do not respond to AntiEGFR therapy, i.e. to cetuximab.

Patients with HNSCC can benefit from antiEGFR therapy (cetuximab) but the treatment predictor (in contrast to CRC-colorectal cancer) is not defined yet. This study aimed to assess the incidence of mutation as a possible predictor of cetuximab treatment in $\mathrm{HN}$ SCC (as in CRC) and evaluate risk factors such as age, gender, location and smoking.

Kit et al studied the frequency of codon 12 mutations and proved that gender does not play any role (19)

In the latter study, 2/11 females had codon 12 mutations $(18.2 \%)$ and 9/11 females were WT (81.8 \%). Both women with codon 12 mutations were older than 52 . As many as $3 / 44$ males in this study had codon 12 mutations (6.82\%) and 41/44 males were WT $(93.18 \%)$. All three men were older than 59 .

Patients with Kras mutations were older than 52 (median 62.8 years) which corresponds with the study conducted by Baskin et al where the same median was stated (62.2 years) (20). One of the reasons why tumors affect mostly older patients can lie in gradual cumulation of mutations. In the hereditary form of tumor disease, just one mutation of a somatic cell is sufficient to eliminate the gene. Whereas in a sporadic form, there is a multilevel process followed by cumulation of mutations in a newly created cell clone.

Mammas et al demonstrated that Kras (and also Nras) mutations occur more in HPV-positive patients, in comparison to HPV-negative patients. In our study, we detected 4 HPV-positive cases and $3 \mathrm{HPV}$-negative cases, which corresponds to the results of Mammas et al (21).

Tumors with mutated codons of the Kras gene were most frequently found in the oropharynx. In the study conducted by Küçük et al, the most tumors with mutated Kras gene were also found in the oropharyngeal area but no close association between tumor location and Kras mutation was observed (22).

The literature describing Kras mutations in condon 146 in HNSCC is insufficient. In our study, we detected 2 mutations (3.63\%) in codon 146, which correlates with the results in the study Loupa- 
kis et al. Current studies are focused mainly on the frequency of mutations and their function as treatment predictors (23).

Our study found a strong correlation between codon $146 \mathrm{mu}-$ tation and HPV infection but this fact does not mean a causal relation between variables while the low amount of input data must be also taken into consideration.

Clinical studies devoted to the Ras gene mutations in HNSCC as possible predictors of cetuximab treatment are focused mainly on Kras mutations. For that reason, the data for comparing Nras mutations with the risk factors in HNSCC are not sufficient.

This study detected Nras mutation in exon 2 in 2/54 patients $(3.7 \%)$, so the frequency was very low. A similar frequency was detected in the study conducted by Irahara et al where mutations of the Nras gene were found in 5/225 patients with CRC (24). The study of Irahara et al confirmed that Nras mutations are less frequent than Kras mutations.

Only one HPV-positive patient had a Nras mutation in exon 2. Statistically, no correlation between Kras and Nras mutations and HPV infection was found. That supports the hypothesis that HPV-induced tumors have a different molecular mechanism of development and do not have so many point mutations (including Kras and Nras) as tumors developed spontaneously.

This study detected one Braf mutation which marginally correlated with laryngeal location of a tumor which was removed with resection boundaries. Due to the single finding of positive Braf mutation, this result (as well as the correlation with gender and age) cannot be regarded as relevant.

V600 is described as the most frequent mutation of the Braf gene. This mutation is also detected in CRC. Our study found c. $1808 \mathrm{G}>\mathrm{A}$ mutation, protein $603 \mathrm{Arg}>\mathrm{Gln}$. This mutation has not been described yet, so its importance as a predictive and/or prognostic factor cannot be defined.

The aim of this work was to find HVP infection in HNSCC and its potential correlation with $\mathrm{P} 16^{\mathrm{INK} 4 \mathrm{~A}}$ and $\mathrm{p} 53$ as a possible diagnostic biomarker.

This work confirmed that IHC can be used as a reliable diagnostic biomarker for HPV-positive HNSCC. IHC also detected a correlation between p53 and HPV-negative HNSCC. Therefore, p53 IHC can be used as a possible prognostic biomarker of HPVnegative HNSCC.

This work also studied the incidence of Ras and Braf mutations in HNSCC and simultaneous influence of risk factors. The study found an association of oropharyngeal tumor location and Kras mutations and a correlation between Kras mutations and smoking. HPV infection correlated with Kras mutations in codon 146 but the data are not statistically significant because the group of patients was quite small.

The found Braf mutation has not been described yet, so we cannot evaluate its predictive and prognostic importance.

The documented data show the necessity of classifying the molecular subtypes of HNSCC and applying individual therapeutic approach on the basis of molecular testing.

\section{References}

1. Garnaes E, Kiss K, Andersen L, Therkildsen MH, Franzmann MB et al. A high and increasing HPV prevalence in tonsillar cancers in Eastern Denmark, 2000-2010: the largest registry-based study to date. Int J Cancer 2015; 136 (9): 2196-203.

2. Polz-gruszka D, Stec A, Dworzański J, Polz-dacewicz M. EBV, HSV, CMV and HPV in laryngeal and oropharyngeal carcinoma in polish patients. Anticancer Res 2015; 1662 (35): 1657-1661.

3. Goldenberg D, Benoit NE, Begum S, Westra WH, Cohen Y, Koch WM, Califano JA. Epstein-Barr virus in head and neck cancer assessed by quantitative polymerase chain reaction. Laryngoscope 2004; 114 (6): 1027-1031.

4. Focchi GRA, Silva IDCG, Nogueira-de-souza NC, Dobo C, Oshima CT, Stavale N. Immunohistochemical expression of p16 (INK4A) in normal uterine cervix, nonneoplastic epithelial lesions, and low-grade squamous intraepithelial lesions. J Low Genit Tract Dis 2007; 11 (2): 98-104.

5. Werness BA, Levine AJ, Howley PM. Association of human papillomavirus types 16 and 18 E6 proteins with p53. Science 1990; 248 (4951): 76 LP-79.

6. Garnett T, Filippova M, Duerksen-Hughes P. Accelerated degradation of FADD and procaspase 8 in cells expressing human papilloma virus 16 E6 impairs TRAIL-mediated apoptosis. Cell Death Differentiation 2007; 13 (11): 1915-1926.

7. Sano T, Oyama T, Kashiwabara K, The TF, Sano T, Oyama T, Shroyer AL. Expression status of p16 protein is associated with human papillomavirus oncogenic potential in cervical and genital lesions. Amer J Pathol 2004; 153 (6): 1741-1748.

8. Mirza A, McGuirk M, Hockenberry TN, Wu Q, Ashar H, Black S, Liu S. Human survivin is negatively regulated by wild-type p53 and participates in p53-dependent apoptotic pathway. Oncogene 2002; 21 (17): 2613-2622.

9. Ang KKP, Harris J, Wheeler R, Weber R, Rosenthal DI, Nguyentân PF, Maura LP. Human papillomavirus and survival of patients with oropharyngeal cancer. New Engl J Med 2011; 363 (1): 24-35.

10. Psyrri A, Rampias T, Vermorken JB. The current and future impact of human papillomavirus on treatment of squamous cell carcinoma of the head and neck. Ann Oncol 2014; 25 (11): 2101-2115.

11. De Vuyst H, Clifford G, Li N, Franceschi S. HPV infection in Europe. Eur J Cancer 2009; 45 (15): 2632-2639.

12. Medsker B, Forno E, Simhan H, Juan C, Sciences R. Human papillomavirus genotype and oropharynx cancer survival in the United States. Eur J Cancer 2016; 70 (12): 773-779.

13. Faust H, Alwan EE, Roslin A, Wennerberg J, Forslund O. Prevalence of human papillomavirus types, viral load and physical status of HPV16 in head and neck squamous cell carcinoma from the South Swedish Health Care Region. J Gen Virol 2016; 97 (11): 2949-2956.

14. Kreimer AR, Clifford GM, Boyle P, Kreimer AR, Clifford GM, Boyle P, Franceschi S. Human papillomavirus types in head and neck squamous cell carcinomas worldwide. Cancer Epidemiol Biomarkers Prev 2005; 14 (2): 467-475.

15. Wittekindt C, Gültekin E, Weissenborn SJ, Pfister HJ, Jens P. Expression of $\mathrm{p} 16$ Protein Is Associated with Human Papillomavirus Status in Tonsillar Carcinomas and Has 2005; 62: 72-80. 


\section{2-838}

16. Nigro JM, Baker SJ, Preisinger C, Jessup JM, Hostetter R, Cleary $\mathbf{K}$, Devilee $\mathbf{P}$. Mutations in the p53 gene occur in diverse human tumour types. Nature 1989; 342 (6250): 705-708.

17. Nadal A, Campo E, Pinto J, Mallofré C, Palacín A, Arias C, Cardesa A. p53 expression in normal, dysplastic, and neoplastic laryngeal epithelium. Absence of a correlation with prognostic factors. J Pathol 1995; 175 (2): 181-188.

18. Halvorsen A, Silwal-Pandit L, Meza-Zepeda L, Vodak D, Vu P, Sagerup C, Helland A. TP53 mutation spectrum in smokers and never smoking lung cancer patients. Front Genet 2016; (5): 1-10.

19. Kit O, Vodolazhskiy D, Gevorkyan Y, Soldatkina N. KRAS gene mutations and gender differences in colorectal cancer. Internat J Biomed 2015; 5 (1): 11-15.

20. Baskin Y, Dagdeviren YK, Calibasi G, Canda AE, Sarioglu S, Ellidokuz H, Oztop I. KRAS mutation profile differences between rectosigmoid localized adenocarcinomas and colon adenocarcinomas. J Gastrointest Oncol 2014; 5 (4): 265-269.
21. Mammas IN, Zafiropoulos A, Sifakis S, Sourvinos G, Spandidos DA. Human papillomavirus (HPV) typing in relation to ras oncogene mRNA expression in HPV-associated human squamous cervical neoplasia. Internat J Biol Markers l'éét'; 20 (4): 257-263.

22. Küçük Ü, Bayol Ü, Usturalı Keskin E, Pala EE, Çukurova İ, Çolak MA, Koç A. Investigating KRAS/BRAF mutation in oropharyngeal squamous cell carcinomas: a preliminary study. J Ear, Nose, Throat 2016; $26(5): 2-4$.

23. Loupakis F, Ruzzo A, Cremolini C, Vincenzi B, Salvatore L, Santini D et al. KRAS codon 61, 146 and BRAF mutations predict resistance to cetuximab plus irinotecan in KRAS codon 12 and 13 wild-type metastatic colorectal cancer. Brit J Cancer 2009; 101 (4): 715-721.

24. Irahara N, Baba Y, Nosho K, Shima K, Yan L, Dias-Santagata D et al. NRAS mutations are rare in colorectal cancer. Diagn Mol Pathol 2010; 19 (3): 157-163.

Received June 18, 2019. Accepted July 6, 2019. 